\title{
PTEN Gene Alteration Positive
}

National Cancer Institute

\section{Source}

National Cancer Institute. PTEN Gene Alteration Positive. NCI Thesaurus. Code C153466.

An indication that mutation, overexpression, fusion or rearrangement involving the PTEN gene has been detected in a sample. 